\title{
Determining the boundaries of the auroral oval from CHAMP field-aligned current signatures - Part 1
}

\author{
C. Xiong ${ }^{1,2}$, H. Lühr ${ }^{1}$, H. Wang ${ }^{2}$, and M. G. Johnsen ${ }^{3}$ \\ ${ }^{1}$ Helmholtz Centre Potsdam, GFZ German Research Centre for Geosciences, Telegrafenberg, 14473 Potsdam, Germany \\ ${ }^{2}$ Department of Space Physics, College of Electronic Information, Wuhan University, 430079 Wuhan, China \\ ${ }^{3}$ Troms $\emptyset$ Geophysical Observatory, Faculty of Science and Technology, University of Troms $\emptyset$, Troms $\varnothing$, Norway \\ Correspondence to: C. Xiong (bear@gfz-potsdam.de)
}

Received: 5 September 2013 - Revised: 5 February 2014 - Accepted: 16 April 2014 - Published: 4 June 2014

\begin{abstract}
In this paper we present the first statistical study on auroral oval boundaries derived from small- and mediumscale field-aligned currents (FACs, $<150 \mathrm{~km}$ ). The dynamics of both the equatorward and poleward boundaries is deduced from 10 years of CHAMP (CHAllenging Minisatellite Payload) magnetic field data (August 2000-August 2010). The approach for detecting the boundaries from FACs works well under dark conditions. For a given activity level the boundaries form well-defined ellipses around the magnetic pole. The latitudes of the equatorward and poleward boundaries both depend, but in different ways, on magnetic activity. With increasing magnetic activity the equatorward boundary expands everywhere, while the poleward boundary shows on average no dependence on activity around midnight, which seems to be stationary at a value of about $72^{\circ}$ Mlat. Functional relations between the latitudes of the boundaries and different magnetic activity indices have been tested. Best results for a linear dependence are derived for both boundaries with the dayside merging electric field. The other indices, like the auroral electrojet (AE) and disturbance storm time (Dst) index, also provide good linear relations but with some caveats. Toward high activity a saturation of equatorwards expansion seems to set in. The locations of the auroral boundaries are practically independent of the level of the solar EUV flux and show no dependence on season.
\end{abstract}

Keywords. Ionosphere (auroral ionosphere) - magnetospheric physics (current systems; magnetosphereionosphere interactions)

\section{Introduction}

The best-known aurora features are the northern and southern auroral ovals (Feldstein, 1963; Feldstein et al., 1969; Akasofu, 1966). They are the regions in the ionosphere which receive the main part of the magnetospheric particle precipitation. The precipitating particles excite atmospheric atoms and molecules and thus cause luminosity both in visible and ultraviolet (UV) wavelengths. Viewed from space with a global imager, the aurora appears as diffuse, continuous, luminous bands that surround both geomagnetic poles at ionospheric altitudes (Frey, 2007). Since the concept of the auroral oval was put forward by Feldstein (1963) and Khorosheva (1967), there have been a large number of observations and models related to this phenomenon (Eather, 1973; Kauristie, 1995; Elphinstone et al., 1996; Yahnin et al., 2006). In general, the auroral oval often consists of two different parts: the discrete oval (visual luminosity, e.g. rays and arcs), which lies embedded in the continuous, permanent diffuse oval. The diffuse oval is mainly equatorward of the discrete oval, but diffuse precipitation, although often subvisual, appears also poleward of the discrete oval. Compared to the diffuse oval the discrete arcs are more dynamic in size, shape, and location within seconds or minutes, with smallscale structures ranging from a few hundred metres to hundreds of kilometres (Borovsky, 1993).

The dynamics of the auroral oval is generally related to the prevailing geomagnetic activity. The exact location of the equatorward oval boundary depends on the energy of the precipitating particles and on the magnetospheric electric and magnetic fields (Kauristie et al., 1999). The poleward boundary of the oval is often taken to separate the closed field 
lines from the polar cap which is covered by open field lines. At the boundary of the polar cap the precipitation energy flux drops significantly. For example, the polar rain within the polar cap is dominated by weak homogeneous fluxes of $<1 \mathrm{keV}$ electrons (Kauristie et al., 1999). During magnetospheric substorms the boundaries of the auroral oval move. In the growth phase, dayside reconnection increases the number of open field lines and consequently the polar cap and the oval expand to lower latitudes. Part of the solar wind energy gets stored as magnetic field energy in the tail lobes of the magnetosphere. During the expansion phase the stored energy is partially dissipated via various processes in the farand near-Earth plasma sheet and in the ionosphere. Due to nightside reconnection the polar cap contracts, as open field lines in the lobe are reconnected to closed field lines (Siscoe and Huang, 1985; Lockwood et al., 1990). Thus the size of the polar cap follows the amount of magnetic field energy stored in the tail lobes, and the locations of the poleward and equatorward boundaries of the oval are important parameters for estimating the energy flows in the solar-windmagnetosphere-ionosphere system (Baker et al., 1997).

The boundaries of the auroral oval can be determined locally by ground-based observations such as radars (Pinnock and Rodger, 2000; Moen et al., 2004; Aikio et al., 2006) or low-altitude satellite observations (Newell et al., 1996; Wang et al., 2005), while optical imagers from high-altitude satellites can provide an instantaneous global view of the auroral oval (Newell et al., 2001; Østgaard et al., 2007). There are also some models for predicting the location of the auroral oval (e.g. Feldstein and Starkov, 1970; Holzworth and Meng, 1975) and the global distribution of the electrons and ions streaming into the ionosphere (Hardy et al., 1985). Based on the energetic spectra measured by the special sensor for precipitating particles on the Defense Meteorological Satellite Program (DMSP), the auroral boundary index (ABI) model is provided to estimate the equatorward boundary of precipitating auroral electrons (Hardy et al., 2008). Boakes et al. (2008) and Longden et al. (2010) presented methods for an automatic detection of the auroral oval boundaries from the Imager for Magnetopause-to-Aurora Global Exploration (IMAGE) satellite. The resulting 2.5-year (2000.052002.10) database of auroral oval boundaries is freely available at the British Antarctic Survey (BAS) server.

Iijima and Potemra (1976) revealed that the currents flowing continuously into and out of the ionosphere appear at locations closely related to the auroral ovals. These currents flowing along geomagnetic field lines are driven by the continuous interaction between the plasma stream from the Sun (solar wind) and the plasma that is bounded magnetically to the Earth. Further, based on Triad magnetometer observations, they found that the large-scale field-aligned current (FAC) sheets are generally aligned with the boundary of the auroral oval, although distortions of this alignment occur during disturbed periods (Iijima and Potemra, 1978). Lühr et al. (1996) introduced an algorithm which allows one under certain assumptions to estimate the field-aligned current density distribution along the track from single spacecraft magnetic field measurements. They have shown that any deviation (oblique crossing or finite extent of current sheet) will lead to an underestimation of the actual current density. Comprehensive studies of the characteristics of FAC signatures derived from CHAMP (CHAllenging Minisatellite Payload) magnetic observations were performed by Ritter et al. (2004) and Wang et al. (2005). Further based on CHAMP data, He et al. (2012) have forwarded a high-resolution empirical model of FAC distribution utilizing orthogonal function analysis.

In this paper we present a statistical study that aims at determining the auroral oval boundaries from CHAMP fieldaligned current signatures. The underlying assumption is that the FAC density is significantly enhanced within the auroral oval. Precipitating particles causing the luminous phenomena enhance also locally the ionospheric conductivity. Therefore we regard our approach for locating the auroral oval as justified. The more than 10 years of continuous magnetic observations with high resolution from CHAMP provide a good basis for such a study. In Sect. 2 we first introduce how to determine FAC density from CHAMP magnetic observation, and then present the approach to detect the auroral oval boundaries. In Sect. 3 the evolution of the auroral oval boundaries in magnetic latitude and magnetic local time in response to magnetic activity will be presented, and we will compare our results with other observations. The characteristics of the auroral boundaries and the comparison of the auroral oval in the two hemispheres will be discussed in Sect. 4.

\section{Data and processing approach}

\subsection{Data sets}

The CHAMP satellite was launched on 15 July 2000 into a circular, near-polar orbit (inclination: $87.3^{\circ}$ ) with an initial altitude of about $456 \mathrm{~km}$. By the end of the mission, 17 September 2010, the orbit had decayed to $250 \mathrm{~km}$. The local time of the orbital plane changed by $1 \mathrm{~h}$ in 11 days, requiring about 130 days to cover all local times.

The fluxgate magnetometer (FGM) onboard CHAMP provided the magnetic field vector readings at a rate of $50 \mathrm{~Hz}$ and a resolution of $0.1 \mathrm{nT}$. The data were calibrated routinely with respect to the onboard absolute scalar Overhauser magnetometer (OVM). A dual-head star camera system mounted together with the FGM on an optical bench provided the orientation of the measured field vectors with arcsecond precision. Data used in this study are the $1 \mathrm{~Hz}$ preprocessed (Level 3) vector data in the sensor frame. 


\subsection{Field-aligned current calculation}

The basic equation for estimating field-aligned currents makes use of the Ampere-Maxwell law:

$\boldsymbol{j}=\frac{1}{\mu_{0}} \nabla \times \boldsymbol{B}$,

where $\boldsymbol{j}$ is the current density vector, $\mu_{0}$ is the vacuum permeability, and $\boldsymbol{B}$ is the magnetic field caused by the currents. For current calculation we make use of the two transverse components in a mean field-aligned (MFA) coordinate system, which is suitable for FAC calculation (Heilig and Lühr, 2013). In the MFA frame the $z$ component is aligned with the ambient magnetic field direction; the $y$ component lies in the horizontal plane and is orthogonal to $z$, pointing towards magnetic east; and the $x$ component completes the triad and points outwards.

For the transformation into the MFA frame we do not follow the rigorous approach, which is based on geomagnetic field data in north-east-centre (NEC) coordinates and which employs main field models (e.g. POMME, Potsdam Magnetic Model of the Earth) for defining the mean field (e.g. Park et al., 2009). In order to avoid the effect of attitude noise, introduced by the uncertainty of the star trackers, when transforming the magnetic field readings into the NEC frame, we make use of the original field measurements in the sensor frame. The "mean field" in our case is derived dynamically from the in situ measurements, low-pass filtered with a cutoff period of $60 \mathrm{~s}$. From the smoothed ambient field readings we compute the local declination and inclination, which are needed to calculate the field components in the MFA frame (e.g. Park et al., 2013). A limitation of this approach is that large-scale features $(>200 \mathrm{~km})$ are suppressed by the way the mean field is determined. The two transverse components $(x, y)$ are usually small and mean-free, while the $z$ component comprises practically the total field strength.

When determining the field-aligned current density from a single satellite, the orientation of the current sheet has to be known. In this study the absolute accuracy of the FAC intensity is of no concern, but we are interested in latitudinal gradients of current density. For that reason we have chosen an efficient and robust approach for calculating FAC densities. In the case of FAC determination from a satellite it is often assumed that the current sheet is traversed at a right angle and that spatial field gradient can be derived from successive field readings along the orbit. Here it is just important that the features of the current sheet do not change abruptly during the boundary crossing.

For the actual calculation of FAC density we make use of an approach introduced by Lühr et al. (1996):

$j_{\|}=\frac{1}{2 \cdot \mu_{0} \cdot \mathrm{d} t}\left(\frac{\mathrm{d} B_{y}^{\prime}}{V_{x}^{\prime}}-\frac{\mathrm{d} B_{x}^{\prime}}{V_{y}^{\prime}}\right) \cdot \frac{1}{\sin (I)}$.

In the frame used here the spacecraft velocity is split into two equal parts $V_{x}^{\prime}$ and $V_{y}^{\prime}$. Also the two transverse $B$ field components, $B_{x}^{\prime}$ and $B_{y}^{\prime}$, are rotated about $B_{z}^{\prime}$ in those directions. Finally, the derived current density is scaled by the sine of the field inclination, $I$, accounting for the angle between ambient $B$ field direction and orbital velocity. The advantage of this approach is that the two velocity components never approach zero and both transverse $B$ field components are taken into account. FAC values for all 10 years of the CHAMP mission have been calculated in this way.

\subsection{Determining the auroral oval boundaries}

An empirical approach for detecting the boundaries of the auroral oval based on the intensity of FACs has been developed. The FAC intensities calculated by the described approach above reflect mainly the small- and medium-scale $(<150 \mathrm{~km})$ field-aligned currents. Larger scales are suppressed by the dynamic calculation of the ambient field direction. The advantage of favouring the smaller-scale FACs is that boundaries appear sharper. Figure 1 shows two examples of FAC activity at auroral latitudes. The left frame is from pre-midnight and the right from noon time. There is in both cases a well-defined latitude range, marked by high FAC intensity, that we associate with the auroral oval. The magnetic apex latitude (Richmond, 1995) used here facilitates a mapping of the detected boundary location at satellite height along geomagnetic field lines down to magnetic latitudes at E layer altitudes $(\sim 110 \mathrm{~km})$.

Following the work of Heilig and Lühr (2013), a variable $S$ has been used to represent the FAC intensity, which is defined as

$S=\left\langle\log _{10} j_{\|}^{2}\right\rangle_{20 s}$.

Here we consider the logarithm of the current density because of the wide range of variations encountered during a boundary crossing. The FAC density, $j$, is given in units of $\mu \mathrm{A} \mathrm{m}^{-2}$. We take averages over $20 \mathrm{~s}$ because this corresponds approximately to $150 \mathrm{~km}$. This scale size is often used as the boundary between small- and large-scale FACs. The values of $S$, a function of latitude, are calculated individually along the four high-latitude auroral segments (from $\pm 40^{\circ}$ apex latitude to the magnetic pole in both hemispheres) for all the CHAMP orbits. Then data from these segments were surveyed subsequently to find the linear parts of the $S$ curve with steep gradients. We start to check from the latitude of maximum $S$ value to lower and higher latitudes for equatorward and poleward boundaries, respectively.

Taking the equatorward boundary as an example for the approach, we start with $S_{\mathrm{C}}$ representing the FAC density at the maximum $S$ value of the considered orbital arc. $S_{\mathrm{C}}$ is compared with a reading $S_{\mathrm{E}}$ further equatorward. We step down $S_{\mathrm{E}}$ until the condition $S_{\mathrm{C}}-S_{\mathrm{E}} \geq 2$ is valid. Then a linear function $S^{*}$ is used to fit to the curve of $S$ over the latitude range from apex latitudes of $S_{\mathrm{C}}$ to $S_{\mathrm{E}}$.

$S^{*}=a \cdot S+b$, 

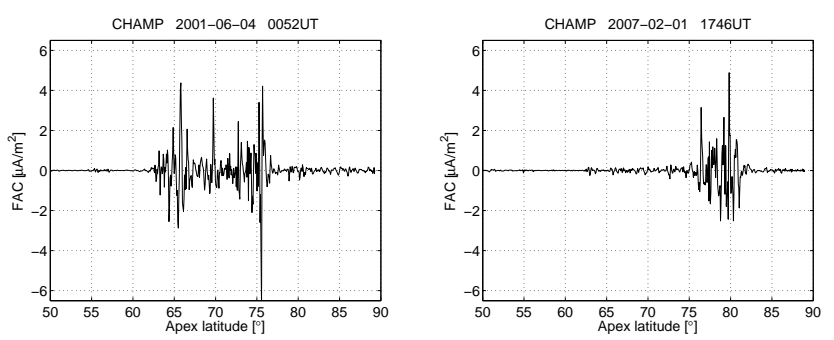

Figure 1. Two examples of FAC in the auroral oval, as derived from CHAMP magnetic field data.

where $a$ and $b$ are the linear fit slope and intercept, respectively, for describing the function $S^{*}$. In a next step we use the error, $\sigma$, to check the quality of the linear fit:

$\sigma=\left.\sqrt{\left\langle\left(S-S^{*}\right)^{2}\right\rangle}\right|_{\mathrm{C}} ^{\mathrm{E}}$

where the boundaries $\mathrm{C}$ and $\mathrm{E}$ represent the start and end point of the linear segment of $S$. If $\sigma$ is larger than 0.25 , we will move $S_{\mathrm{C}}$ to the next latitude data point. Otherwise, we consider the data from $S_{\mathrm{C}}$ to $S_{\mathrm{E}}$ as a good linear part. Subsequently $S_{\mathrm{E}}$ is advanced to lower latitude until $\sigma$ becomes larger than 0.25 . To find the exact start and end point of this linear segment, the $S_{\mathrm{C}}$ to $S_{\mathrm{E}}$ will be further extended to their nearest inflection point of the $S$ curve. Then $S_{\mathrm{C}}$ is stepped forward until the two conditions are met again. This process continues until $S_{\mathrm{E}}$ has reached the lowest apex latitude $\left(40^{\circ}\right)$ of the considered orbital arc. From all accepted linear segments the steepest is selected for final consideration. At last we choose from this segment the mid-point between $S_{\mathrm{C}}$ and $S_{\mathrm{E}}$ to represent the equatorial boundary of the auroral oval.

Figure 2 illustrates for two examples the detection procedure described above. The $S$ curves correspond to the two FAC measurements shown in Fig. 1. In the first example from 4 June 2001, the auroral oval is crossed by CHAMP in the pre-midnight sector at 21:48 and 21:54 MLT (magnetic local time) for the equatorward and poleward boundaries, respectively, while in the second example from 1 February 2007 the auroral oval is detected around the noon sector at 11:23 and 11:35 MLT for the equatorward and poleward boundaries, respectively. Comparing the two examples, we find that the auroral oval around noon is much narrower than that in the premidnight sector, and it is located at higher magnetic latitudes. In both events large and fluctuating FAC densities are found within the detected auroral oval. The statistical significance of these observations will be evaluated in the following sections.

\section{Statistical results}

For studying the characteristics of the auroral oval we have used 10 years of CHAMP observations from August 2000 to August 2010, during which 114956 CHAMP segments were
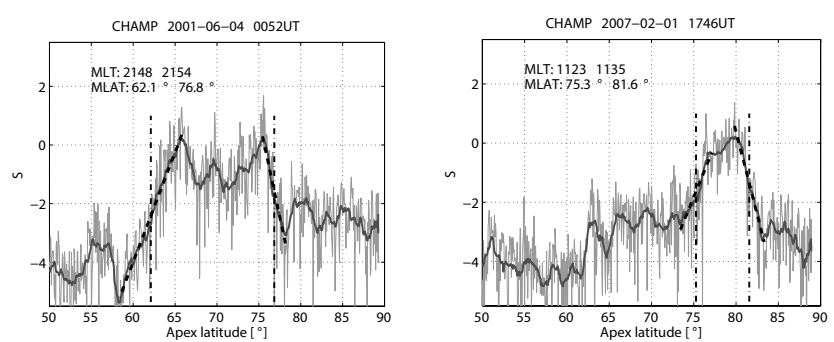

Figure 2. Boundaries (dashed-dot lines) of the auroral oval for the two examples of CHAMP FAC signatures as shown in Fig. 1. For the detection approach see text.

analysed for both hemispheres. We first checked the reliability of the auroral boundary detection depending on ambient conditions. We found that the location of both boundaries is scattering a lot when they are determined in sunlit regions. As a consequence we considered also the solar zenith angle at $110 \mathrm{~km}, \chi$, and only the events in darkness with $\chi \geq 90^{\circ}$ have been taken into account. As described above, our aim is to find the best linear parts of the latitude profile with steep gradients, so we discard the detections when the slope of the linear fit in Eq. (4) was too small (i.e. $|a|<0.2$ ) or the deviation, $\sigma$, in Eq. (5) was too large (i.e. $\sigma>0.4$ ). We will justify the values selected here for the parameters in Sect. 4.1. These criteria reduced the data set to 50091 and 43936 detections for the equatorward and poleward auroral boundaries in the Northern Hemisphere, as well as 44044 and 37228 detections in the Southern Hemisphere.

For test purposes we grouped the detections in the beginning by certain criteria in order to find out whether certain condition bias the results. For example, the detection yield during the first 5 years of high solar activity (mean $F 10.7=$ $160 \mathrm{sfu}$ ) was compared with that of the second 5 years during solar minimum (mean $F 10.7=81 \mathrm{sfu}$ ). Furthermore, as the magnetic pole in the Southern Hemisphere is further away from the geographic pole than in the Northern Hemisphere, we initially treated the events in the two hemispheres separately. Figure 3 presents the magnetic local time distribution of the detected events separately for the two activity periods and two hemispheres. We can see that the local time distribution of detected events is much the same in all four frames. There seems to be neither a hemispheric- nor solar-activitydependent bias of our approach. The local time distribution is solely controlled by the imposed solar zenith angle condition $\left(\chi>90^{\circ}\right)$. The EAB and PAB represent the equatorward auroral boundary and poleward auroral boundary, respectively. We can see that in each MLT bin there are at least 500 detections, except for the EAB in the Northern Hemisphere around noon (09:00-15:00 MLT). These large numbers allow for investigating various aspects of the boundaries dynamics. 

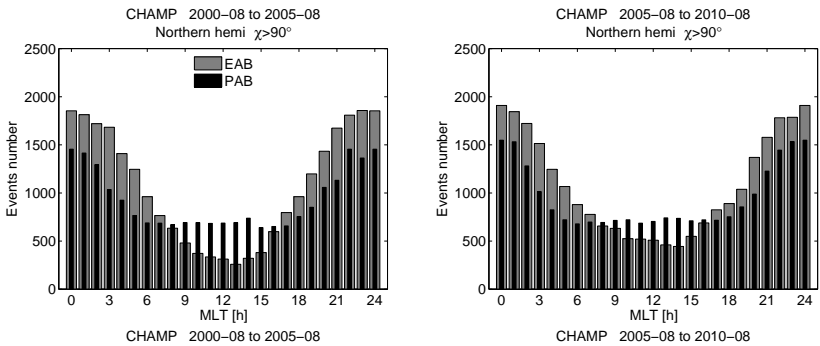

Southern hemi $x>90^{\circ}$
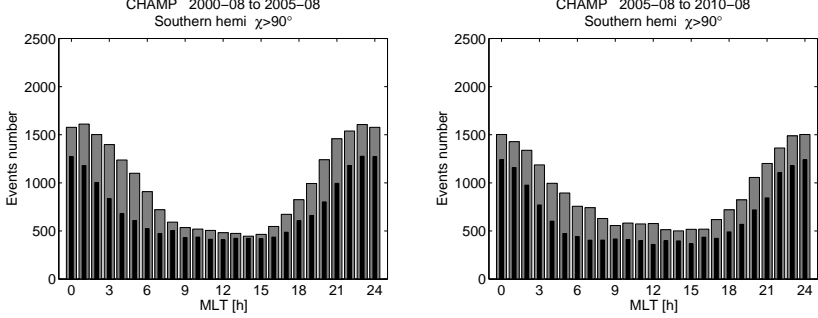

Figure 3. The magnetic local time distribution of the auroral boundary detections during high (left) and low (right) solar activity years separately for both hemispheres.

\subsection{Magnetic latitude and MLT distribution of the auroral oval in the Northern Hemisphere}

It is known that the shape and size of the auroral oval varies with magnetic activity, and there exists a morningevening, day-night asymmetry of the auroral oval. To investigate these properties we divide all the events into three classes: quiet $(K p<2)$, moderate $(2 \leq K p \leq 4)$, and disturbed $(\mathrm{Kp}>4)$ magnetic activities. The individual detections are plotted in Fig. 4 as dots in a polar plot. Black dots mark the equatorward boundary and red the poleward boundary. For disturbed conditions the statistical significance already becomes marginal. During other times we find a clear grouping of the boundary location around centre latitudes at the various local times.

Figures 5 and 6 present latitude profiles of the occurrence rates of CHAMP boundary detections in four different $2 \mathrm{~h}$ wide MLT bins under different magnetic activity levels. We have selected local time sectors to present the distributions around dawn, noon, dusk, and midnight. In all eight frames the latitude profiles of occurrence rates resemble quite well Gaussian normal distributions. For that reason our sample of detections can be regarded as suitable for statistical analysis, and the latitudes at peak values can be taken as representative for an activity level. Looking at Fig. 5 we find for moderate activity peaks of the equatorward boundary distribution at magnetic latitudes of $65^{\circ}, 74^{\circ}, 63^{\circ}$, and $62^{\circ}$ for the dawn, noon, dusk, and midnight sectors, respectively. These results reflect very well the known displacement of the auroral oval to the nightside by about $4^{\circ}$ in latitude. With increasing magnetic activity, the equatorward boundary in all these four MLT sectors expands to lower latitudes. The poleward boundaries presented in Fig. 6 show a somewhat different dependence on activity. For moderate conditions we find

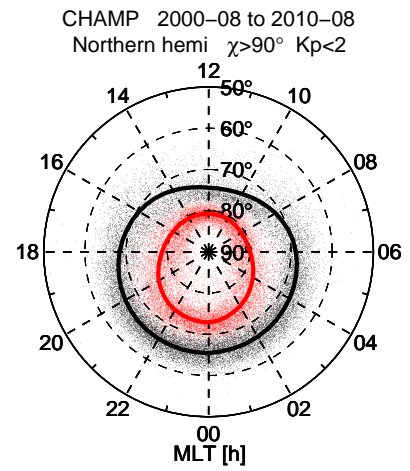

CHAMP 2000-08 to 2010-08 Northern hemi $\chi>90^{\circ} \mathrm{Kp}=2 \sim 4$

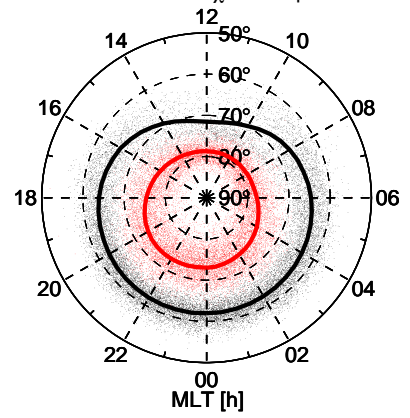

CHAMP 2000-08 to 2010-08 Northern hemi $\chi>90^{\circ} \mathrm{Kp}>4$

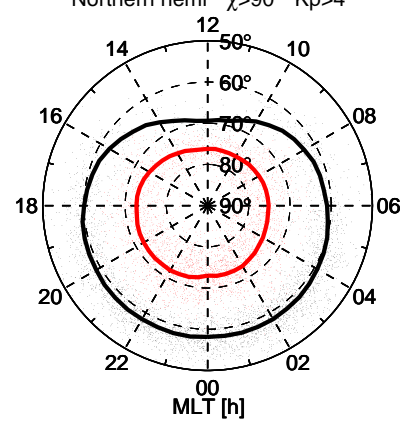

Figure 4. Distribution of equatorward (black) and poleward (red) boundary detections; solid lines are the mean latitudes of $0.5 \mathrm{~h}$ bins. Events have been grouped into three magnetic activity classes controlled by the Kp index: quiet (top), moderate (middle), and disturbed (bottom). Only northern hemispheric results are presented.

peaks of the distribution at magnetic latitudes of $78^{\circ}, 78^{\circ}$, $75^{\circ}$, and $72^{\circ}$ for the dawn, noon, dusk, and midnight sectors, respectively. The obtained latitude around noon is consistent with earlier reports (e.g. Feldstein and Starkov, 1970). In the dawn, noon, and dusk sectors the boundary moves to lower latitudes with increasing magnetic activity, while the boundary around midnight seems to be stationary on average at a value of about $72^{\circ}$ Mlat, showing little dependence on magnetic activity. This can be regarded as an interesting observation.

For a more quantitative analysis average latitudes from all the hourly MLT bins have been used to fit ellipses to the two 

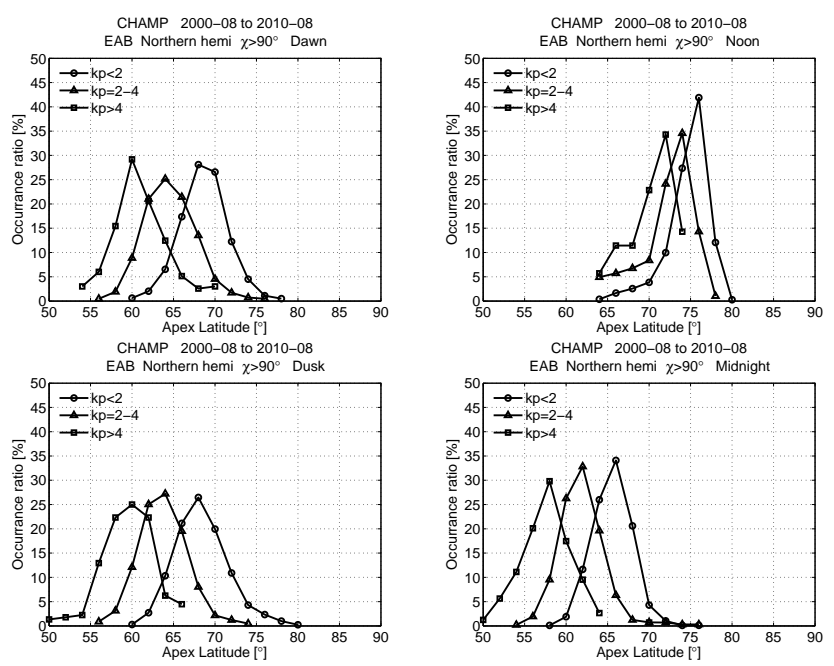

Figure 5. Activity dependence of the equatorward auroral boundary latitude distribution for different MLT sectors: dawn (top left), noon (top right), dusk (bottom left), and midnight (bottom right).

boundaries, separately for both the hemispheres and the three levels of activity. The resulting ellipse parameters are listed in Table 1. The parameters semi ${ }_{x}$ and semi ${ }_{y}$ are the semi-axis of the ellipse in midnight-noon and dawn-dusk directions, respectively; $x_{0}$ and $y_{0}$ are the coordinates of the ellipse centre, with positive value of $x$ and $y$ pointing towards midnight and dawn, respectively; and $\varphi_{0}$ is the orientation angle of the ellipse between semi $i_{x}$ and midnight-noon axis, with positive values counting anti-clockwise. All the length scales are in degree of latitude. We find a good agreement within the level of uncertainties between the results in the two hemispheres. This adds to the confidence in our boundary detection approach.

The results listed in Table 1 can be used to visualize the shape of the auroral oval. Figure 7 presents the auroral region as a shaded area for the three activity levels in the Northern Hemisphere. Comparing the auroral oval under different magnetic activities, although in general both boundaries move to lower latitudes with increasing magnetic activity, obvious MLT difference can be seen. Under magnetically quiet conditions, the ellipse centres of both boundaries are clearly displaced to midnight, and the equatorward boundary is more circular than the poleward boundary. With increasing magnetic activity, the ellipse centre of the equatorward boundary stays close to $85.5^{\circ} \mathrm{Mlat}$ in the midnight sector and the boundaries move to lower latitude at all MLTs almost at the same rate. The magnetic latitude of the poleward boundary shows almost no dependence on magnetic activity on the nightside, while at other local times it expends equatorward. The difference in MLT behaviour of the two boundaries causes a broadening of the auroral oval primarily on the nightside and early morning, but keeps the width almost constant around noon.
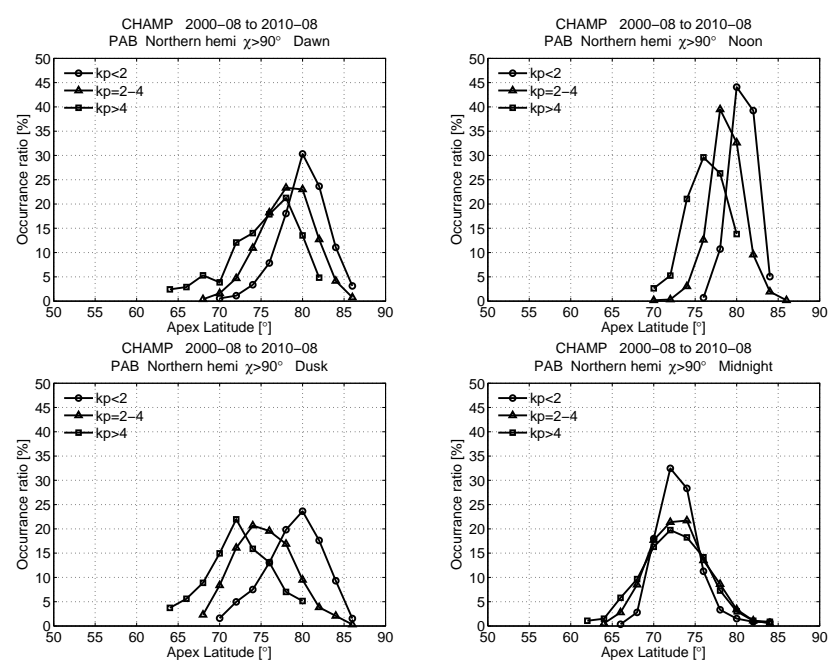

Figure 6. Same as Fig. 5, but for the poleward auroral boundary.

\subsection{The auroral oval and the activity indices}

As a next step we want to find out which indices are best suited to characterize the expansion of the auroral oval. Figure 8 presents the dependence of the magnetic latitude of the auroral boundary on the three considered indices, merging electric field $\left(E_{\mathrm{m}}\right)$, auroral electrojet (AE) index, and disturbance storm time (Dst) index. For all these indices hourlyaveraged values have been used. The apex latitudes of the detections were first sorted into bins covering a certain range of the index, then the mean apex latitudes of the bins were used for further correlation coefficient analyses. The merging electric field is calculated according to the coupling function as defined by Newell et al. (2007):

$E_{\mathrm{m}}=V_{\mathrm{sw}}{ }^{\frac{4}{3}}\left(\sqrt{B_{y}^{2}+B_{z}^{2}}\right)^{\frac{2}{3}} \sin ^{\frac{8}{3}}\left(\frac{\theta}{2}\right)$

where $V_{\mathrm{sw}}$ denotes the solar wind velocity, $B_{y}$ and $B_{z}$ denote the $y$ and $z$ components of the interplanetary magnetic field (IMF) in geocentric solar magnetospheric (GSM) coordinates, and $\theta$ is the clock angle of the IMF $\left(\tan (\theta)=\frac{\left|B_{y}\right|}{B_{z}}\right)$. In order to make $E_{\mathrm{m}}$ comparable with the merging electric field defined by Kan and Lee (1979), for Eq. (6) we use $V_{\mathrm{sw}}$ in units of $\mathrm{km} \mathrm{s}^{-1}, B_{y}$ and $B_{z}$ in nT, and lastly divided the value by a factor of 1000 . In particular, for $E_{\mathrm{m}}$ and $\mathrm{AE}$, "the memory effect" of the magnetosphere-ionosphere system was taken into account. We follow the approach of Werner and Pröss (1997):

$E_{\mathrm{m} 6}=\frac{\sum_{i=0}^{6} E_{\mathrm{m}}(\mathrm{UT}-i[\mathrm{~h}]) e^{-i}}{\sum_{i=0}^{6} e^{-i}}$,

where $E_{\mathrm{m} 6}$ is a weighted mean of the hourly-averaged $E_{\mathrm{m}}$ for the actual hour and the previous $6 \mathrm{~h}$; UT denotes the universal 
Table 1. The ellipse parameters of the auroral oval boundaries in both hemispheres for different magnetic activities.

\begin{tabular}{|c|c|c|c|c|c|c|c|}
\hline \multirow[t]{2}{*}{ Auroral oval } & & \multicolumn{3}{|c|}{ Northern Hemisphere } & \multicolumn{3}{|c|}{ Southern Hemisphere } \\
\hline & & $\mathrm{Kp}<2$ & $2 \leq \mathrm{Kp} \leq 4$ & $\mathrm{Kp}>4$ & $\mathrm{Kp}<2$ & $2 \leq \mathrm{Kp} \leq 4$ & $\mathrm{Kp}>4$ \\
\hline \multirow{5}{*}{$\operatorname{EAB}\left({ }^{\circ}\right)$} & $\operatorname{semi}_{x}$ & 20.07 & 23.55 & 26.86 & 19.61 & 22.93 & 26.63 \\
\hline & $\operatorname{semi}_{y}$ & 21.93 & 26.38 & 30.48 & 20.86 & 24.91 & 29.09 \\
\hline & $\varphi_{0}$ & -2.37 & -1.91 & 0.53 & -4.91 & -10.74 & -6.23 \\
\hline & $x_{0}$ & 4.19 & 4.21 & 4.72 & 3.72 & 3.93 & 4.51 \\
\hline & $y_{0}$ & -0.41 & -0.42 & -0.30 & -0.59 & -0.56 & -0.36 \\
\hline \multirow[t]{5}{*}{$\operatorname{PAB}\left({ }^{\circ}\right)$} & $\operatorname{semi}_{x}$ & 13.25 & 14.23 & 15.73 & 13.69 & 14.92 & 17.18 \\
\hline & $\operatorname{semi}_{y}$ & 11.34 & 13.77 & 16.19 & 13.07 & 15.29 & 17.67 \\
\hline & $\varphi_{0}$ & -4.78 & -14.10 & 8.76 & -8.92 & -2.26 & -26.64 \\
\hline & $x_{0}$ & 4.16 & 3.02 & 1.83 & 3.77 & 2.98 & 1.68 \\
\hline & $y_{0}$ & -0.63 & -1.11 & -1.28 & -1.10 & -1.25 & -1.31 \\
\hline
\end{tabular}

time in hours of the observation. From Fig. 8 (left) we can see that all these three indices reveal satisfactory linear relationships with the magnetic latitude of the equatorward auroral boundary. The blue asterisks are the mean value of the bin, and the black line denotes the standard deviation of the bin. The correlation coefficients are as high as 0.94 , while a clear non-linear relationship can be seen for small $\mathrm{AE}_{6}$ when $\mathrm{AE}_{6} \leq 80 \mathrm{nT}$, and a non-linear relationship is found for positive values of Dst, when Dst $\geq 0 \mathrm{nT}$.

Figure 8 (right) presents the relation between the magnetic latitude of the poleward auroral boundary and merging electric field, auroral electrojet index, and Dst index. The linear fit parameters and correlation coefficients have been listed in Table 2. As we have seen in Fig. 6 the magnetic latitude of the poleward boundary around midnight shows little dependence on magnetic activity; therefore only the detections within a time window from 08:00 to 16:00 MLT have been taken into account in the correlation. As expected, all these four indices show quite good linear relationships with the magnetic latitude of the poleward boundary. Similar to the equatorward boundary a non-linear relationship can be found again for positive values of Dst.

In order to check a possible solar flux influence on the latitudes of the auroral boundaries, we have performed correlation analyses similar to those with magnetic activity indices. To avoid a leakage of the magnetic activity dependence into the analysis on solar flux we considered for the boundary location only detections from the activity class quiet $(\mathrm{Kp}<2)$. Calculations were performed independently for the two hemispheres. The results reveal little to no dependence of the auroral oval on solar flux, as shown in Fig. 9. Over the whole solar flux range, $P 10.7$ between 60 and $250 \mathrm{sfu}$ $(P 10.7=0.5 \cdot(F 10.7+F 10.7 a)$, where $F 10.7 a$ is an average of the solar flux index $F 10.7$ over 81 days), the equatorward boundary shows in both hemispheres only a small and not significant change of $2.5^{\circ}$ in latitude, while the poleward boundary remains fully unchanged. This result confirms that all the auroral oval expansions shown in Fig. 8 can be attributed solely to magnetic activity.

\subsection{Comparison with DMSP, IMAGE, and MSP observations}

In order to see how well our approach determines the boundaries of the auroral oval from CHAMP FAC data, we made comparisons with observations from other facilities. Examples are taken from DMSP, IMAGE, and the Meridian Scanning Photometer (MSP) observations on Svalbard. The DMSP satellites sample polar regions at about $835 \mathrm{~km}$ altitude along orbits at fixed local times. One of the satellites (F15) has an 09:30-21:30 MLT orbit. The IMAGE spacecraft aimed to study the global response of the Earth's magnetosphere to changes in the solar wind. It was placed in a $1000 \mathrm{~km} \times 46000 \mathrm{~km}$ orbit around the Earth, with an inclination of $90^{\circ}$ (passing over the poles). Onboard of IMAGE, the far ultraviolet (FUV) imaging system instrument employs three detectors, among which the Wideband Imaging Camera (WIC) is designed to view the whole Earth and the auroral oval at satellite distances greater than $4 R_{\mathrm{E}}$ (Frey et al., 2001). The MSP used for this study is located close to Longyearbyen $\left(78.2^{\circ} \mathrm{N}, 15.8^{\circ} \mathrm{E}\right)$, Svalbard. It utilizes a fivechannel photometer consisting of a rotating mirror that scans from north to south along the geomagnetic meridian, as well as narrow band tilted interference filters and photomultiplier tubes. The data is given as emission intensity in Rayleighs as a function of time and scan angle, ranging from $0^{\circ}$ (northern horizon) to $180^{\circ}$ (southern horizon). The auroral emission wavelengths monitored typically are $630 \mathrm{~nm}[\mathrm{OI}]$ and $557.7 \mathrm{~nm}[\mathrm{OI}]$ (Johnsen et al., 2012).

Figure 10 presents an example from 17 March 2007, when CHAMP and DMSP F15 flew across the northern polar region almost at the same time. Figure 10 (left) shows the Pedersen conductance, $\Sigma_{\mathrm{P}}$, estimated from DMSP particle measurements (top), as well as CHAMP FAC observation (bottom). CHAMP and DMSP crossed the northern magnetic 
Table 2. Linear fit parameters and correlation coefficients between the apex latitudes of the auroral oval boundaries and various indices.

\begin{tabular}{rrrrrrrrrr}
\hline & & \multicolumn{3}{c}{ Northern Hemisphere } & & \multicolumn{3}{c}{ Southern Hemisphere } \\
\cline { 3 - 4 } \cline { 8 - 9 } & & $E_{\mathrm{m} 6}$ & $\mathrm{AE}_{6}$ & Dst & & $E_{\mathrm{m} 6}$ & $\mathrm{AE}_{6}$ & Dst \\
\hline \multirow{2}{*}{$\mathrm{EAB}\left(^{\circ}\right)$} & $\mathrm{a}$ & -0.7110 & -0.0108 & 0.0789 & & -0.7070 & -0.0113 & 0.0850 \\
& $\mathrm{~b}$ & 67.92 & 66.25 & 65.59 & & 69.17 & 68.48 & 66.91 \\
& $\mathrm{cc}$ & 0.944 & 0.934 & 0.934 & & 0.930 & 0.947 & 0.945 \\
\hline \multirow{2}{*}{$\mathrm{PAB}\left(^{\circ}\right)$} & $\mathrm{a}$ & -0.5294 & -0.0109 & 0.0595 & & -0.5503 & -0.0095 & 0.0735 \\
& $\mathrm{~b}$ & 81.28 & 80.98 & 80.03 & & 80.46 & 80.45 & 78.94 \\
& $\mathrm{cc}$ & 0.922 & 0.947 & 0.923 & & 0.943 & 0.927 & 0.907 \\
\hline
\end{tabular}

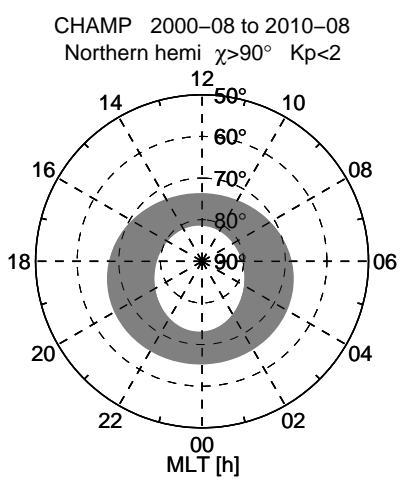

CHAMP 2000-08 to 2010-08 Northern hemi $\chi>90^{\circ} \quad \mathrm{Kp}=2 \sim 4$

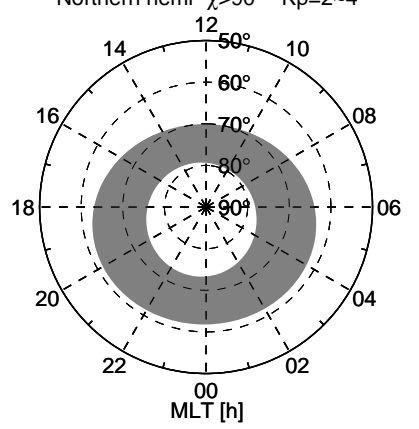

CHAMP 2000-08 to 2010-08

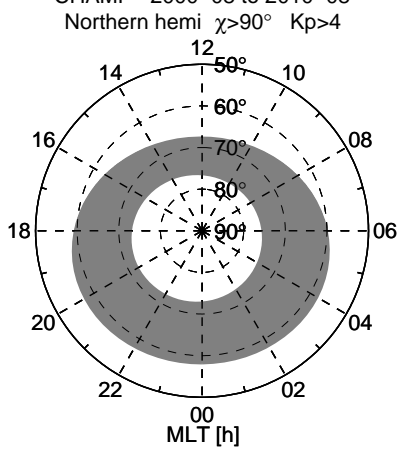

Figure 7. Ellipses fitted to the auroral oval boundaries in the Northern Hemisphere during quiet (top), moderate (middle), and disturbed (bottom) magnetic activities.
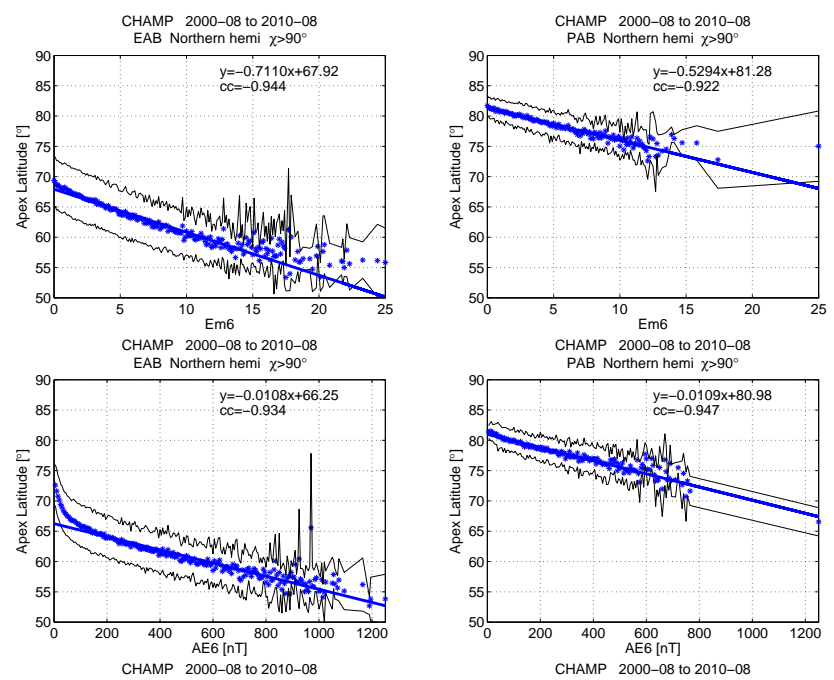
EAB Northern hemi $x>90^{\circ}$
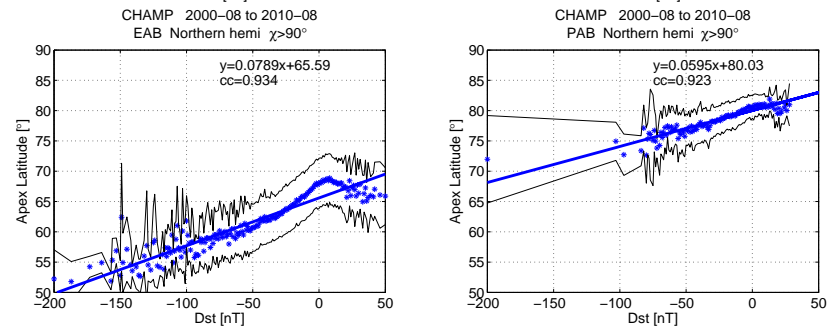

Figure 8. The dependence of the auroral boundary latitude on merging electric field (top), auroral electrojet index (middle), and Dst index (bottom). For the equatorward boundary (left) all local times from 00:00 to 24:00 MLT are considered, while for the poleward boundary (right) only detections from the time sector 08:00 to 16:00 MLT have been used. The blue asterisks are the mean values of activity bins, and the black lines denote the standard deviation of the bin values.

pole at 20:38 and 20:55 UT, respectively. For the DMSP observation, the calculation of $\Sigma_{\mathrm{P}}$ as well as the method for auroral oval detection can be found in details in Wang et al. (2008). We first calculate the auroral Pedersen conductance along the DMSP path and find the peak conductance, then stepping equatorward and poleward until the conductance is reduced to 0.25 times the peak value. In this way the equatorward and poleward boundaries of the auroral oval 

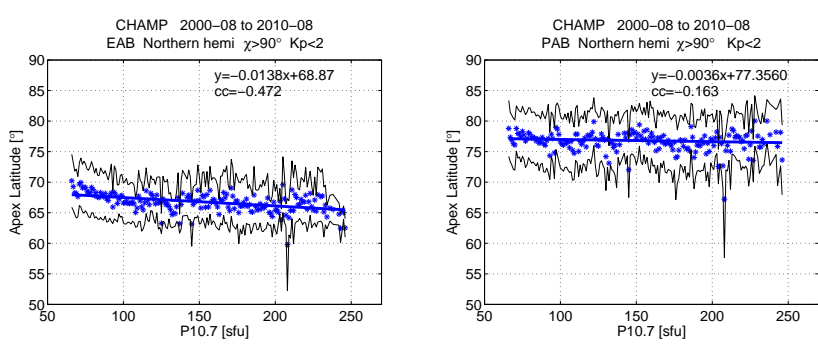

Figure 9. The dependence of the auroral boundary latitude on the solar flux index $P 10.7$. For the equatorward boundary (left) all local times from 00:00 to 24:00 MLT are considered, while for the poleward boundary (right) only detections from the time sector 08:00 to 16:00 MLT have been used. The blue asterisks are the mean values of activity bins, and the black lines denote the standard deviation of the bin values.

are derived from DMSP observation at 68.0 and $75.4^{\circ}$ Mlat. From CHAMP FAC observation the two boundaries are found at 67.3 and $73.3^{\circ}$ Mlat. Although the boundaries deduced from CHAMP and DMSP observations are not exactly at the same location, when taking the MLT into account, the slight differences of the two boundaries are acceptable. Especially for the equatorward boundary, where the MLT difference between the two satellites is $17 \mathrm{~min}$, the boundary estimates differ only by $0.8^{\circ}$ Mlat. Comparing the latitudinal distributions of $\Sigma_{\mathrm{P}}$ and FAC, we find that the Pedersen conductance is enhanced where the FAC densities are larger. Differences between the two satellite results seem to be caused mainly by the individual definitions of the thresholds for the boundaries. Figure 10 (right) shows the trajectories of CHAMP (solid) and DMSP (dashed); the equatorward and poleward boundaries have been marked by crosses and circles with different colours (red for DMSP F15 and blue for CHAMP).

Figure 11 presents a comparison between CHAMP and IMAGE observations on 1 December 2002, at about 14:38 UT. The CHAMP satellite passed the northern magnetic pole at 14:38 UT, and the FAC observations are separated into dawnside (top) and duskside (bottom) events, as shown in Fig. 11 (left). The dashed lines in the left frames mark the boundaries of the auroral oval determined from FAC signatures. We can see that the equatorward and poleward boundaries appear at 67.4 and $72.7^{\circ}$ Mlat on the dawnside, and 60.6 and $72.5^{\circ}$ Mlat on the duskside, respectively. Larger-amplitude FACs can be found inside the auroral oval. Figure 11 (right) shows a simultaneous observation of the auroral oval from IMAGE FUV-WIC observation at about 14:37 UT. The blue crosses and circles are the boundaries determined from CHAMP FAC observations, as shown by the dashed lines in the left frames. We can see that the boundaries determined from FAC are highly consistent with the IMAGE observation. Corresponding to the narrow band of brightness at about $70^{\circ}$ Mlat on the dawnside, there are large-amplitude FACs at the same location, as observed by CHAMP.
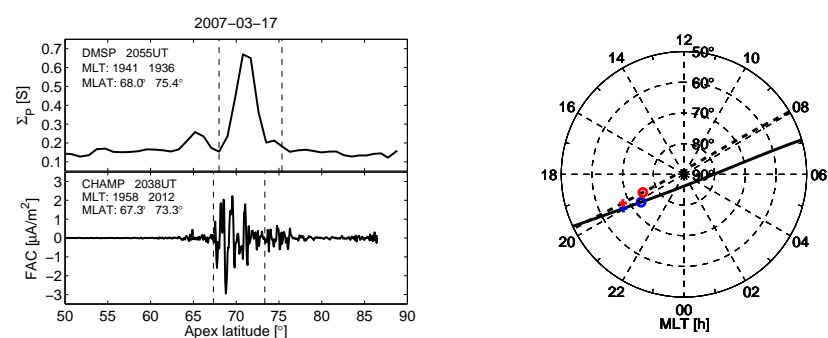

Figure 10. (left) Latitude profiles of Pedersen conductance, $\Sigma_{\mathrm{P}}$, estimated from DMSP F15 obserservation (top) and CHAMP FAC observations (bottom) almost at the same time on 17 March 2007. (right) The trajectories of DMSP (dashed) and CHAMP (solid); the equatorward and poleward boundaries of the auroral oval have been marked as crosses and circles, respectively, with different colours on the trajectories (red for DMSP and blue for CHAMP).
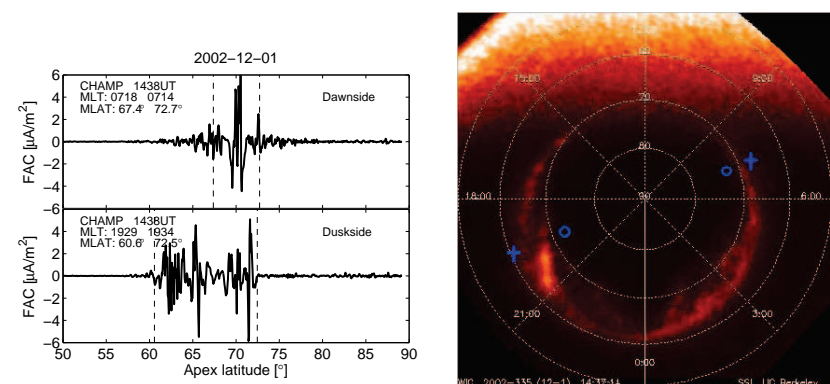

Figure 11. (left) CHAMP FAC observations in the Northern Hemisphere at 14:38 UT both at dawn- (top) and duskside (bottom) on 1 December 2002. The boundaries of the auroral oval have been marked with dashed lines. (right) Simultaneous observation of the auroral oval in the Northern Hemisphere from IMAGE FUV-WIC observations at 14:37:11 UT; the blue crosses and circles are the boundaries determined from CHAMP FAC observations.

Figure 12 presents the auroral intensity at $630 \mathrm{~nm}$ as a function of time and Mlat, as measured by the MSP on 15 January 2001. The emission was mapped to MLat using an altitude of $268 \mathrm{~km}$. This corresponds to the peak altitude of the reference cusp aurora defined by Johnsen et al. (2012), which is based on precipitation characteristics and atmospheric and ionospheric conditions considered by them to be close to average. The open-closed field line boundary (OCB) deduced from optical features is indicated as a solid black line, with error margins indicated by dashed black lines. CHAMP passed over the MSP at about 08:10 UT. The equatorward and poleward auroral boundaries determined from FAC signatures appear at $74.5^{\circ}$ and $78.1^{\circ}$ Mlat, respectively. Comparing the results from the two observations we can see that there is good agreement. The boundaries found from CHAMP are located well within the edge of the auroral oval/particle precipitation in the dayside. All these comparisons with alternative techniques provide further evidence for the reliability of the auroral oval boundaries derived from small-scale FAC distributions. 

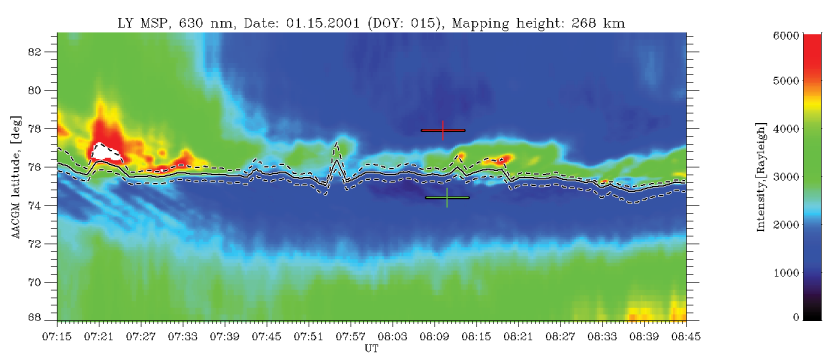

Figure 12. The auroral $630 \mathrm{~nm}$ intensity as a function of time and Mlat as measured by the MSP on 15 January 2001. The equatorward and poleward oval boundaries derived from CHAMP FAC observation are marked with green and crosses, respectively.

\section{Discussion}

In the previous sections we have described our attempts to localize the auroral oval from its small-scale FAC signatures. The underlying physics is that the conductivity is locally enhanced supporting stronger FACs. The prime reason for that is precipitating particles. They create the colourful auroras but also cause a significant enhancement of $E$ region conductivity. Because of the close connection between aurora and conductivity we consider our FAC approach as suitable for localizing the boundaries of the auroral oval. This inference is supported by the observation that our boundary detections are much more uncertain in sunlit regions where solar radiation adds to the E region conductivity, thus reducing the contrast. It may be regarded as a certain limitation of our technique that we can make use of FAC signatures only in region where the Sun is below the horizon, but also optical techniques have problems in sunlight.

\subsection{The parameters in the empirical approach}

Our empirical approach for detecting the boundaries of the auroral oval is based on the intensity of FACs. Several parameters are used to find the linear segment of $S$, as defined in Eq. (3). For justification of the parameter thresholds used in Sect. 2.3, we employed the auroral oval boundaries derived from the IMAGE satellite WIC observations as a reference. The 2.5-year (2000-2002) database of auroral oval boundaries is freely available at the BAS server. The BAS auroral boundaries are given every 2-3 min with a resolution of $1 \mathrm{~h}$ in magnetic local time. Additionally, the poleward auroral boundary has been calibrated by DMSP particle precipitation measurements (Longden et al., 2010). For our comparison, we set the UT difference between CHAMP and IMAGE WIC observations to less than $2 \mathrm{~min}$, and only good detections have been taken for comparison where the boundary difference between the two sets is less than $2^{\circ}$ in magnetic latitude. With these criteria, 1560 and 1449 common detections have been found for the equatorward and poleward boundaries, respectively.

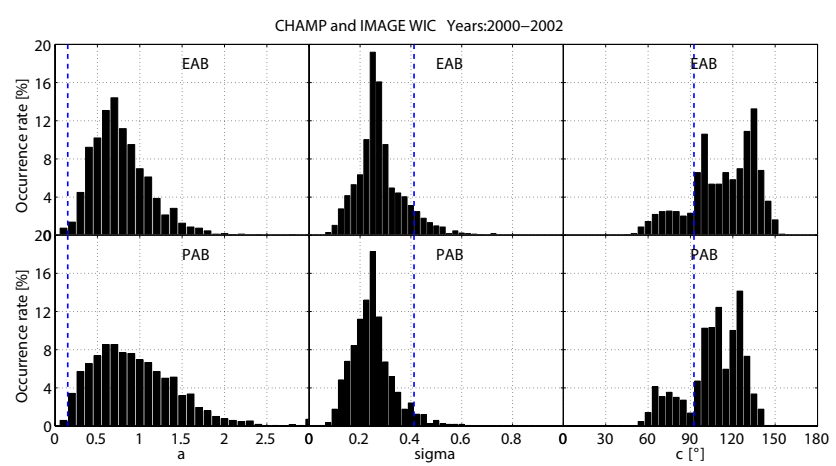

Figure 13. The distribution of occurrence rates for good common detections between CHAMP FAC and BAS auroral boundaries catalogue. The blue dashed lines mark the threshold values of the parameters used in our procedure.

Figure 13 presents the distribution of occurrence rates for the parameters $a$ (left), $\sigma$ (middle), and $\chi$ (right) from events with good agreement between CHAMP and IMAGE. There is a fast increase in good detections when the slope of the linear segment is larger than 0.2 , and most of the detections are for uncertainties, $\sigma,<0.4$. For that reason the thresholds of $a$ and $\sigma$ have been set to 0.2 and 0.4 , respectively. As we already mentioned, in our approach the location of the auroral oval boundaries are scattering a lot when they are determined in sunlit regions. The occurrence rates of good events increases fast when the solar zenith angle at $110 \mathrm{~km}$ altitude is larger than $90^{\circ}$. Therefore, $\chi=90^{\circ}$ was used to distinguish dayside and nightside observations. The boundaries determined in our approach are more reliable on the nightside.

\subsection{Characteristics of the auroral boundaries}

It has long been known that the auroral oval moves equatorwards at times of enhanced magnetic activity. It was Størmer in 1910 who first argued that a current encircling the Earth in the equatorial plane is needed to shift the artificial auroras of Birkeland's terrella experiment to latitudes where they are actually observed on the ground (Egeland and Burke, 2012). Our observation of a linear relation between Dst and the boundary latitude, as well as other studies (e.g. Schulz, 1997; Lühr and Maus, 2010), confirm the relation between ring current strength and equatorward displacement of the aurora.

For quantitative studies we have investigated the dependence of the auroral oval location on several activity indices. These analyses are performed independently on the equatorward and poleward boundaries. Different physical processes are believed to be responsible for the two locations. The euqatorward boundary expands to lower latitudes everywhere with increasing magnetic activity. This can be interpreted as the response to a contracting ring current. To test the relation we used different indices to quantify activity. The merging 

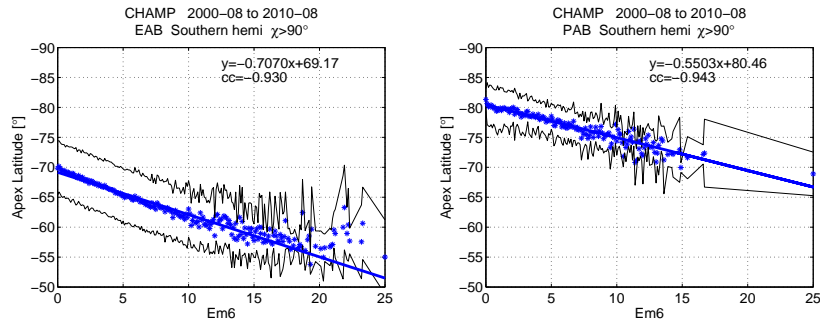

CHAMP $2000-08$ to $2010-08$
EAB Southern hemi $x>90^{\circ}$

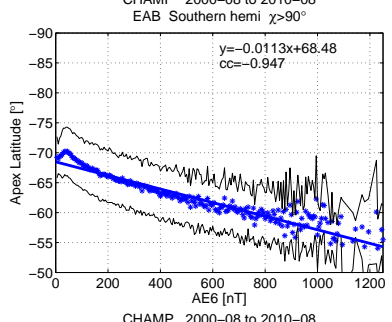

CHAMP $2000-08$ to $2010-08$
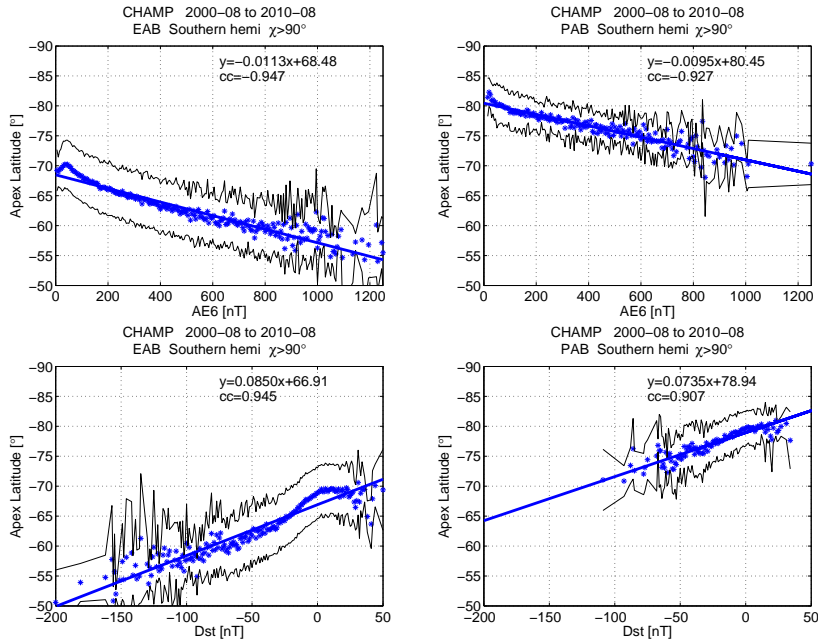

CHAMP $2000-08$ to $2010-08$
PAB Southern hemi $x>90^{\circ}$

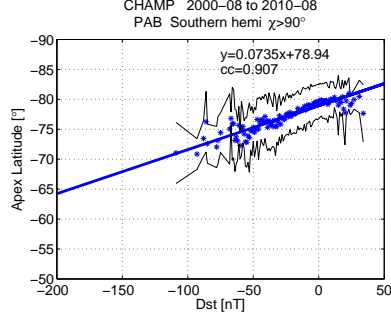

Figure 14. The same as Fig. 8, but for the Southern Hemisphere.

electric field, $E_{\mathrm{m}}$, also termed "Newell coupling function" (Newell et al., 2007), quantifies the solar wind input into the magnetosphere. We find a very good linear relation to the latitude of the boundary (see Fig. 8) when the $E_{\mathrm{m}}$ values of past hours are also taken into account. This favourable result is consistent with the report of Newell et al. (2007). In our Figs. 8 and 14, a saturation of the auroral equatorward boundary can be seen in both hemispheres when $E_{\mathrm{m} 6}>20$. A similar effect has been reported for the relation between $E_{\mathrm{m}}$ and the cross polar cap potential, $\Phi_{\mathrm{PC}}$ (e.g. Nagatsuma, 2002). Our observations confirm that the coupling efficiency seems to become smaller for strong solar wind driving. Conversely, it should be noted that Liu et al. (2010) found no saturation effect when investigating the solar wind energy input into the thermosphere during magnetic storms.

More recent alternative versions of the coupling function $E_{\mathrm{m}}$ have been proposed (e.g. Milan et al., 2012; Tenfjord and Østgaard, 2013). These coupling functions generally express in a similar way the reconnection electric field or the rate at which magnetic flux is opened at the dayside magnetopause. We have tested these alternative coupling functions but could not find an improvement of the linear relation with the latitude of the auroral boundaries.

Another index we tested is the auroral electrojet index, which reflects the local time average of the electrojet strength in the northern auroral oval. This index also yields a good linear correlation with the displacement of the auroral boundary. However, there is a caveat to be considered. At low AE values ( $\mathrm{AE}<50 \mathrm{nT}$ ) the linear relation vanishes (see Fig. 8). At very low activity the recording stations are obviously so far away from the electrojet that they cannot track its strength property. A similar effect is observed for the Southern Hemisphere (see Fig. 14).

As mentioned before there exists a causal relation between ring current strength and equatorward displacement. Our analysis confirms the relation in principle, but in detail three different ranges have been found. (1) As is obvious from Fig. 8, for positive values of the Dst index, the auroral oval moves also equatorward. (2) There is an almost perfect linear relation with the latitude of the boundary for Dst in the range of -90 to $0 \mathrm{nT}$. (3) For lower Dst, corresponding to stronger ring current fields, a saturation effect sets in, preventing the equatorward boundary to expand to too-low latitudes. This observation is consistent with earlier reports on a midlatitude saturation of the oval expansion during the major storms in fall 2003 by Wang et al. (2006). Particularly interesting is the reversal of the correlation for positive Dst values. Such readings are primarily from times when the magnetosphere is highly compressed, e.g. after a sudden storm commencement (SSC) (Maltsev, 2004). Also that condition seems to cause an equatorwards displacement of the auroral oval. Sudden compressions obviously cause precipitation from the inner region of the ring current that shift R2 FACs to lower latitudes.

The poleward boundary of the oval exhibits somewhat different responses to magnetic activity. In particular around midnight there is no net response to the level of activity observed. On the other hand, it is known that the polar cap boundary is moving up and down during a substorm cycle. This transient motion related to events is not resolved here but is probably the reason for the width of the distribution shown in Fig. 6 around midnight. Conversely around noon, the poleward boundary is closely controlled by the solar wind input. Figure 8 (right) reveals that there is an excellent linear correlation with all the indices considered. However, the range of index values containing boundary detections is much reduced compared to that of the equatorward boundary. This indicates that the detection of the poleward boundary is often not successful during highly disturbed conditions.

As a result of our correlation analysis we may conclude that the modified merging electric field (Newell coupling function) is a suitable quantity for parameterizing the location of both boundaries.

\subsection{Comparison of the auroral oval in the two hemispheres}

As we mentioned above, the magnetic pole in the Southern Hemisphere is further away from the geographic pole than in the Northern Hemisphere. The auroral oval in the south may thus show different behaviours. The ellipse parameters of both the auroral boundaries in the south are also listed 
Table 3. The polar cap area and estimated open magnetic flux in the two hemispheres.

\begin{tabular}{lrrrrrrrr}
\hline & \multicolumn{3}{c}{ Northern Hemisphere } & & \multicolumn{3}{c}{ Southern Hemisphere } \\
\cline { 2 - 3 } & $\mathrm{Kp}<2$ & $2 \leq \mathrm{Kp} \leq 4$ & $\mathrm{Kp}>4$ & & $\mathrm{Kp}<2$ & $2 \leq \mathrm{Kp} \leq 4$ & $\mathrm{Kp}>4$ \\
\hline Area $\left(10^{12} \mathrm{~m}^{2}\right)$ & 5.191 & 6.775 & 8.807 & & 6.184 & 7.886 & 10.490 \\
Flux $(\mathrm{GWb})$ & -0.306 & -0.399 & -0.521 & & 0.369 & 0.467 & 0.620 \\
\hline
\end{tabular}

in Table 1. Similar to the Northern Hemisphere, the equatorward boundaries move to lower latitudes at a comparable rate with increasing magnetic activity at all MLTs, while the poleward boundary around midnight seems to be stationary on average. The largest difference between the two hemispheres appears during quiet magnetic conditions, with the polar cap being more circular in the Southern Hemisphere. Also the centres of the ellipses are slightly less displaced from the geomagnetic pole. Further, we have checked the relations of the boundaries to merging electric field, auroral electrojet index, and Dst index. Results are shown in Fig. 14. Very similar results compared to the Northern Hemisphere are obtained (see linear fit parameters and correlation coefficients in Table 2). Just for the correlation with the Dst are differences somewhat larger.

It is known that the poleward boundary encircling the polar cap is often related to the open-closed field line boundary. Our analysis offers the possibility of estimating the polar cap area and with that the amount of open flux for different activity levels. Based on the ellipse parameters in Table 1, we calculated the northern polar cap area as $5.2 \times 10^{12}, 6.8 \times 10^{12}$, and $8.8 \times 10^{12} \mathrm{~m}^{2}$ for the three activity classes. In the Southern Hemisphere the areas are larger by about $20 \%$ (see Table 3). For physical reasons the open magnetic flux in both hemispheres has to be the same. To check this we calculated the open flux, $\phi$, encircled by our poleward boundaries. The basic equation is

$\phi=\int_{A} B_{Z} \cdot \mathrm{d} A$,

where $A$ represents the polar cap area and $B_{Z}$ the vertical magnetic field component. For the integration we divided the polar cap area in $110 \mathrm{~km} \times 110 \mathrm{~km}$ bins and added up the $B_{Z}$ values at the centre point as obtained from the International Geomagnetic Reference Field (IGRF). Obtained results are listed in Table 3. The magnetic flux from the southern polar cap is also found to be larger than in the Northern Hemisphere for all the magnetic activity levels. At present we cannot offer a conclusive explanation for this hemispheric difference. The poleward edge of our auroral oval based on smalland medium-scale FACs is obviously not identical with the open-closed field line boundary. Nevertheless we think that the variation of our polar cap area is a reasonable measure for the open flux change in the magnetospheric tail. The magnetic effect at Earth surface of the tail field is of concern for geomagnetic field modellers. This component adds to the ring current field and needs to be corrected independently of the Dst value. Lühr and Maus (2010) have shown that the near-Earth effect of the tail currents exhibits no solar cycle effect when only magnetically quiet $(\mathrm{Kp}<3)$ periods are considered. Equally, we found here that the polar cap area is independent of solar flux level (see Fig. 9). All these results suggest that open flux calculated from auroral oval estimates could be used, after proper calibration, for predicting the tail current effect at Earth surface.

\section{Summary}

In this paper we have presented the first statistical study on auroral oval boundaries derived from small- and mediumscale field-aligned currents. The dynamics of both the equatorward and poleward boundaries are deduced from 10 years of CHAMP magnetic field data (August 2000-August 2010). Major results obtained are the following:

1. The approach for detecting the boundaries of enhanced FAC intensity works well under dark conditions. In sunlit areas many more false detections are encountered.

2. The latitudes of the equatorward and poleward boundaries both depend, but in different ways, on magnetic activity. For a given activity level the boundaries form well-defined ellipses around the magnetic poles, getting larger with increasing activity. The equatorward boundary expands everywhere, while the poleward boundary shows on average no dependence on activity around midnight. Since the poleward boundary moves to lower latitudes only at local time sectors away from midnight, the shape of the auroral oval changes significantly with magnetic activity.

3. Functional relations between the latitudes of the boundaries and magnetic activity have been tested for three different indices. Best results for a linear dependence are derived for both boundaries with the merging electric field (also called the Newell coupling function). Besides that other indices, like AE and Dst, also provide good linear relations but with some caveats. Toward high activity a saturation of equatorward expansion seems to set in. 
4. The locations of the auroral boundaries are practically independent of the level of the solar EUV flux. We also could not find any generic seasonal dependence.

The results presented here and the favourable comparisons with other methods of defining auroral boundaries are in favour with our detection method based on small-scale FACs. As a consequent next step we have constructed an empirical model for the auroral boundaries called $\mathrm{CH}$-Aurora2014. This is described in an accompanying paper (Xiong and Lühr, 2014). There we also present a detailed validation of the derived boundary locations.

Acknowledgements. The authors thank Jan Rauberg and Patricia Ritter for scientific discussion about field-aligned current data. The Longyearbyen Meridian Scanning Photometer is owned by the University Centre in Svalbard (UNIS). The staff at UNIS and the Kjell Henriksen Observatory are thanked for operating and providing the MSP data. The ACE, DMSP, and IMAGE teams, as well as the World Data Center C2, Kyoto, are acknowledged for providing the data. The BAS auroral boundary data were derived and provided by the British Antarctic Survey based on IMAGE satellite data. The CHAMP mission was sponsored by the Space Agency of the German Aerospace Center (DLR) through funds of the Federal Ministry of Economics and Technology. The work of Chao Xiong at GFZ is supported by the Alexander von Humboldt Foundation through a Research Fellowship for Postdoctoral Researchers.

The service charges for this open access publication have been covered by a Research Centre of the Helmholtz Association.

Topical Editor C. Owen thanks G. Chisham and A. Aikio for their help in evaluating this paper.

\section{References}

Aikio, A. T., Pitkänen, T., Kozlovsky, A., and Amm, O.: Method to locate the polar cap boundary in the nightside ionosphere and application to a substorm event, Ann. Geophys., 24, 1905-1917, doi:10.5194/angeo-24-1905-2006, 2006.

Akasofu, S.-I.: The auroral oval, the auroral substorm and their relations with the internal structure of the magnetosphere, Planet. Space Sci., 14, 587-595, 1966.

Baker, D. N., Pulkkinen, T. I., Hesse, M., and McPherron, R. L.: A quantitative assessment of energy storage and release in the Earth's magnetotail, J. Geophys. Res., 102, 7159-7168, doi:10.1029/96JA03961, 1997.

Boakes, P. D., Milan, S. E., Abel, G. A., Freeman, M. P., Chisham, G., Hubert, B., and Sotirelis, T.: On the use of IMAGE FUV for estimating the latitude of the open/closed magnetic field line boundary in the ionosphere, Ann. Geophys., 26, 2759-2769, doi:10.5194/angeo-26-2759-2008, 2008.

Borovsky, J. E.: Auroral arc thicknesses as predicted by various theories, J. Geophys. Res., 98, 6101-6138, 1993.

Eather, R. H.: The auroral oval-A reevaluation, Rev. Geophys., 11, $155-167,1973$
Egeland, A. and Burke, W. J.: The ring current: a short biography, Hist. Geo Space. Sci., 3, 131-142, doi:10.5194/hgss-3-131-2012, 2012.

Elphinstone, R. D., Murphree, J. S., and Cogger, L. L.: What is a global auroral substorm?, Rev. Geophys., 34, 169-232, 1996.

Feldstein, Y. I.: Some problems concerning the morphology of auroras and magnetic disturbances at high latitudes, Geomagn. Aeronomy, 3, 183-195, 1963.

Feldstein, Y. I. and Starkov, G. V.: The auroral oval and the boundary of closed field lines of geomagnetic field, Planet. Space. Sci., 15, 501-508, 1970.

Feldstein, Y. I., Isaev, S. I., and Lebedinsky, A. L.: Phenomenology and morphology of aurorae, Ann. Int. Quiet Sun Year, 4, 311$348,1969$.

Frey, H. U.: Localized aurora beyond the auroral oval, Rev. Geophys., 45, RG1003, doi:10.1029/2005RG000174, 2007.

Frey, H. U., Mende, S. B., Carlson, C. W., Gérard, J.-C., Hubert, B., Spann, J., Gladstone, R., and Immel, T. J.: The electron and proton aurora as seen by IMAGE-FUV and FAST, Geophys. Res. Lett., 28, 1135-1139, 2001.

Hardy, D. A., Gussenhoven, M. S., and Holeman, E.: A statistical model of auroral electron precipitation, J. Geophys. Res., 90, 4229-4248, 1985.

Hardy, D. A., Holeman, E. G., Burke, W. J., Gentile, L. C., and Bounar, K. H.: Probability distributions of electron precipitation at high magnetic latitudes, J. Geophys. Res., 113, A06305, doi:10.1029/2007JA012746, 2008.

He, M., Vogt, J., Lühr, H., Sorbalo, E., Blagau, A., Le, G., and Lu, G.: A high-resolution model of field-aligned currents through empirical orthogonal functions analysis (MFACE), Geophys. Res. Lett., 39, L18105, doi:10.1029/2012GL053168, 2012.

Heilig, B. and Lühr, H.: New plasmapause model derived from CHAMP field-aligned current signatures, Ann. Geophys., 31, 529-539, doi:10.5194/angeo-31-529-2013, 2013.

Holzworth, R. and Meng, C.: Mathematical representation of the auroral oval, Geophys. Res. Lett., 2, 337-380, 1975.

Iijima, T. and Potemra, T.: Field-aligned currents in the dayside cusp observed by triad, J. Geophys. Res., 81, 5971-5979, 1976.

Iijima, T. and Potemra, T.: The amplitude distribution of fieldaligned currents associated with substorms, J. Geophys. Res., 83, 599-615, 1978.

Johnsen, M. G., Lorentzen, D. A., Holmes, J. M., and Løvhaug, U. P.: A model based method for obtaining the open/closed field line boundary from the cusp auroral $6300 \AA$ AOI ] red line, J. Geophys. Res., 117, A03319, doi:10.1029/2011JA016980, 2012.

Kan, J. R. and Lee, L. C.: Energy coupling function and solar windmagnetosphere dynamo, Geophys. Res. Lett., 6, 577-580, 1979.

Kauristie, K.: Statistical fits for auroral oval boundaries during the substorm sequence, J. Geophys. Res., 100, 21885-21895, 1995.

Kauristie, K., Weygand, J., Pulkkinen, T. I., Murphree, J. S., and Newell, P. T.: Size of the auroral oval: UV ovals and precipitation boundaries compared, J. Geophys. Res., 104, 2321-2331, 1999.

Khorosheva, O. V.: Spatial-temporal distribution of aurorae, in Aurorae, No. 16, 1-84, Academy of Sciences, Moscow, 1967 (in Russian).

Liu, R., Lühr, H., Doornbos, E., and Ma, S.-Y.: Thermospheric mass density variations during geomagnetic storms and a prediction model based on the merging electric field, Ann. Geophys., 28, 1633-1645, doi:10.5194/angeo-28-1633-2010, 2010. 
Lockwood, M., Cowley, S. W. H., and Freeman, M. P.: The excitation of plasma convection in the high latitude ionosphere, J. Geophys. Res., 95, 7961-7972, 1990.

Longden, N., Chisham, G., Freeman, M. P., Abel, G. A., and Sotirelis, T.: Estimating the location of the open-closed magnetic field line boundary from auroral images, Ann. Geophys., 28, 1659-1678, doi:10.5194/angeo-28-1659-2010, 2010.

Lühr, H. and Maus, S.: Solar cycle dependence of quiet-time magnetospheric currents and a model of their near-Earth magnetic fields, Earth Planets Space, 62, 843-848, 2010.

Lühr, H., Warnecke, J., and Rother, M. K. A.: An algorithm for estimating field-aligned currents from single spacecraft magnetic field measurements: A diagnostic tool applied to Freja satellite data, Geosci. Remote Sens., 34, 1369-1376, 1996.

Maltsev, Y. P.: Points of controversy in the study of magnetic storms, Space Sci. Rev., 110, 227-277, 2004.

Milan, S. E., Gosling, J. S., and Hubert, B.: Relationship between interplanetary parameters and the magnetopause reconnection rate quantified from observations of the expanding polar cap, J. Geophys. Res., 117, A03226, doi:10.1029/2011JA017082, 2012.

Moen, J., Lockwood, M., Oksavik, K., Carlson, H. C., Denig, W. F., van Eyken, A. P., and McCrea, I. W.: The dynamics and relationships of precipitation, temperature and convection boundaries in the dayside auroral ionosphere, Ann. Geophys., 22, 1973-1987, doi:10.5194/angeo-22-1973-2004, 2004.

Nagatsuma, T.: Saturation of polar cap potential by intense solar wind electric fields, Geophys. Res. Lett., 29, 1422, doi:10.1029/2001GL014202, 2002.

Newell, P. T., Meng, C.-I., and Lyons, K. M.: Suppression of discrete aurorae by sunlight, Nature, 381, 766-767, 1996.

Newell, P. T., Liou, K., Sotirelis, T., and Meng, C.-I.: Polar Ultraviolet Imager observations of global auroral power as a function of polar cap size and magnetotail stretching, J. Geophys. Res., 106, 5895-5905, doi:10.1029/2000JA003034, 2001.

Newell, P. T., Sotirelis, T., Liou, K., Meng, C.-I., and Rich, F. J.: A nearly universal solar wind-magnetosphere coupling function inferred from 10 magnetospheric state variables, J. Geophys. Res., 112, A01206, doi:10.1029/2006JA012015, 2007.

Østgaard, N., Mende, S. B., Frey, H. U., Sigwarth, J. B., Aasnes, A., Weygand, J.: Auroral conjugacy studies based on global imaging, J. Atmos. Sol.-Terr. Phys., 69, 249-255, 2007.

Park, J., Lühr, H., Stolle, C., Rother, M., Min, K. W., and Michaelis, I.: The characteristics of field-aligned currents associated with equatorial plasma bubbles as observed by the CHAMP satellite, Ann. Geophys., 27, 2685-2697, doi:10.5194/angeo-27-26852009, 2009.

Park, J., Lühr, H., and Rauberg, J.: Global characteristics of Pc1 magnetic pulsations during solar cycle 23 deduced from CHAMP data, Ann. Geophys., 31, 1507-1520, doi:10.5194/angeo-311507-2013, 2013.
Pinnock, M. and Rodger, A. S.: On determining the noon polar cap boundary from SuperDARN HF radar backscatter characteristics, Ann. Geophys., 18, 1523-1530, doi:10.1007/s00585-0011523-2, 2000.

Richmond, A. D.: Ionospheric electrodynamics using magnetic apex coordinates, J. Geomagn. Geoelectr., 47, 191-212, 1995.

Ritter, P., Lühr, H., Maus, S., and Viljanen, A.: High-latitude ionospheric currents during very quiet times: their characteristics and predictability, Ann. Geophys., 22, 2001-2014, doi:10.5194/angeo-22-2001-2004, 2004.

Schulz, M.: Direct influence of ring current on auroral oval diameter, J. Geophys. Res., 102, 14149-14154, doi:10.1029/97JA00827, 1997.

Siscoe, G. L. and Huang, T. S.: Polar cap inflation and deflation, J. Geophys. Res., 90, 543-547, 1985.

Tenfjord, P. and Østgaard, N.: Energy transfer and flow in the solar wind-magnetosphere-ionosphere system: A new coupling function, J. Geophys. Res., 118, 5659-5672, doi:10.1002/jgra.50545, 2013.

Wang, H., Lühr, H., and Ma, S. Y.: Solar zenith angle and merging electric field control of field-aligned currents: A statistical study of the Southern Hemisphere, J. Geophys. Res., 110, A03306, doi:10.1029/2004JA010530, 2005.

Wang, H., Ma, S. Y., Lühr, H., Liu, Z. X., Pu, Z. Y., Escoubet, C. P., Frey, H. U., Réme, H., and Ritter, P.: Global manifestations of a substorm onset observed by a multi-satellite and ground station network, Ann. Geophys., 24, 3491-3496, doi:10.5194/angeo-243491-2006, 2006.

Wang, H., Ridley, A. J., Lühr, H., Liemohn, M. W., and Ma, S. Y.: Statistical study of the subauroral polarization stream: Its dependence on the cross-polar cap potential and subauroral conductance, J. Geophys. Res., 113, A12311, doi:10.1029/2008JA013529, 2008.

Werner, S. and Prölss, G. W.: The position of the ionospheric trough as a function of local time and magnetic activity, Adv. Space Res., 20, 1717-1722, 1997.

Xiong, C. and Lühr, H.: An empirical model of the auroral oval derived from CHAMP field-aligned current signatures - Part 2, 32, 623-631, doi:10.5194/angeo-32-623-2014, 2014.

Yahnin, A. G., Despirak, I. V., Lubchich, A. A., Kozelov, B. V., Dmitrieva, N. P., Shukhtina, M. A., and Biernat, H. K.: Relationship between substorm auroras and processes in the near-Earth magnetotail, Space Sci. Rev., 122, 97-106, 2006. 